\title{
The influence of the presence of gasses in mineral oil on the ability of molecular sieves for water sorption
}

\author{
Mateusz Cybulski ${ }^{1}$, Piotr Przybylek ${ }^{1}$ \\ ${ }^{1}$ Poznan University of Technology, Institute of Electric Power Engineering, Piotrowo 3A, 60-965 Poznan, Poland
}

\begin{abstract}
Previous studies has shown, that for the same relative humidity, the ability of molecular sieves to adsorb water in the air is higher than in mineral oil. One of the reasons for this difference may be the presence of dissolved gasses in the mineral oil. The effect of the presence of gasses in mineral oil on the ability of molecular sieves to adsorb water was experimentally investigated. Samples of non-degassed and degassed mineral oil with a similar initial water content were dried by means of activated $3 \mathrm{~A}$ and $13 \mathrm{X}$ molecular sieves. The obtained results allowed to show that in the studied range of gas content in oil they do not affect the ability of molecular sieves for water sorption.
\end{abstract}

\section{Introduction}

In the publication [1], an experiment based on the drying of mineral transformer oil by means of molecular sieves $3 \mathrm{~A}$ and $13 \mathrm{X}$ was described. The tests confirmed the high potential of the molecular sieves for drying mineral oil. It was also found that the final relative saturation of water in oil of the analyzed samples was higher than expected. The expected final water content in oil after drying, was estimated on the basis of sorption isotherms of molecular sieves determined in the air. One of the reasons for the discrepancy between the amount of water adsorbed by molecular sieves in the air and the amount of water adsorbed in the oil may be related to the presence of dissolved gas molecules in the oil [2]. This publication examines the effect of the influence of gasses dissolved in mineral oil on the ability of molecular sieves for water sorption.

Knowledge of the interactions between molecular sieves and gasses dissolved in the oil is very important from the point of view of the use of molecular sieves for drying the transformer insulation system. This issue is particularly important in the aspect of:

- determination of water sorption isotherms in insulating liquids, which are necessary to assess the effectiveness of transformer insulation drying using molecular sieves,

- adsorption of gasses from insulating liquid, which are used for diagnostics of transformers by means of Dissolved Gas Analysis (DGA) method [3].

The aim of the research was to examine the influence of the presence of dissolved gasses in mineral oil on the ability of $3 \mathrm{~A}$ and $13 \mathrm{X}$ molecular sieves for water sorption. For this purpose, the degassed and non degassed transformer oil was dried with the abovementioned molecular sieves. The analyzed parameters were water content in oil samples before and after the drying process and gas content in oil.

\section{The influence of the presence of gasses in mineral oil on the ability of molecular sieves for water sorption - research}

\subsection{Measurement procedure}

In order to investigate the effect of the presence of dissolved gasses in mineral oil on the ability of molecular sieves for water sorption, it was necessary to prepare two oil samples with a similar water content and significantly different dissolved gasses content. Samples were prepared in the following manner. The first sample was exposed to air. As a result, atmospheric gasses, in particular nitrogen, oxygen and carbon dioxide could be dissolved in it. A second sample was degassed by heating for $13 \mathrm{~h}$ in a vacuum chamber at $80^{\circ} \mathrm{C}$. The pressure in the chamber ranged from $0.5 \mathrm{mbar}$ to 2.0 mbar. The water content in the samples was then measured using the Karl Fischer titration method [4]. The water content in the non-degassed sample was 24 ppm, whereas in the degassed sample it was $8 \mathrm{ppm}$. In connection with the difference in sample moisture formed after the degassing process, an appropriate amount of water was added to the degassed oil sample using a microlitre syringe. The oil was then sealed in an airtight vessel and left on a magnetic stirrer for the water to dissolve. After $96 \mathrm{~h}$, the water content in the samples was again measured using the Karl Fischer titration method. The measured water content was $26 \mathrm{ppm}$ in non-degassed oil and $22 \mathrm{ppm}$ in degassed oil. The analyzed samples were also examined by gas chromatography to determine the initial dissolved gas 
content. The prepared oil was placed in six bottles with a capacity of $650 \mathrm{ml}$. The first three bottles were filled with non-degassed oil, three more were filled with degassed oil. Molecular sieves were added to four bottles in accordance with Table 1.

Table 1. List of prepared samples.

\begin{tabular}{|c|c|}
\hline Sample number & The contents of the bottle \\
\hline 1 & Non-degassed oil (blank test) \\
\hline 2 & Degassed oil (blank test) \\
\hline 3 & $\begin{array}{c}\text { Non-degassed oil } \\
+0,0804 \mathrm{~g} 3 \text { A molecular sieve }\end{array}$ \\
\hline 4 & $\begin{array}{c}\text { Degassed oil } \\
+0,0834 \mathrm{~g} 3 \text { A molecular sieve }\end{array}$ \\
\hline 5 & $\begin{array}{c}\text { Non-degassed oil } \\
+0,0791 \mathrm{~g} \text { 13X molecular sieve }\end{array}$ \\
\hline 6 & $\begin{array}{c}\text { Degassed oil } \\
+0,0817 \mathrm{~g} 13 \mathrm{X} \text { molecular sieve }\end{array}$ \\
\hline
\end{tabular}

\subsection{Results and conclusions}

Figure 1 shows the total content of gasses dissolved in degassed and non-degassed oil before the experiment. The sum of gasses was calculated by adding concentrations of the following gasses: $\mathrm{CO}, \mathrm{CO}_{2}, \mathrm{~N}_{2}$ and $\mathrm{O}_{2}$.

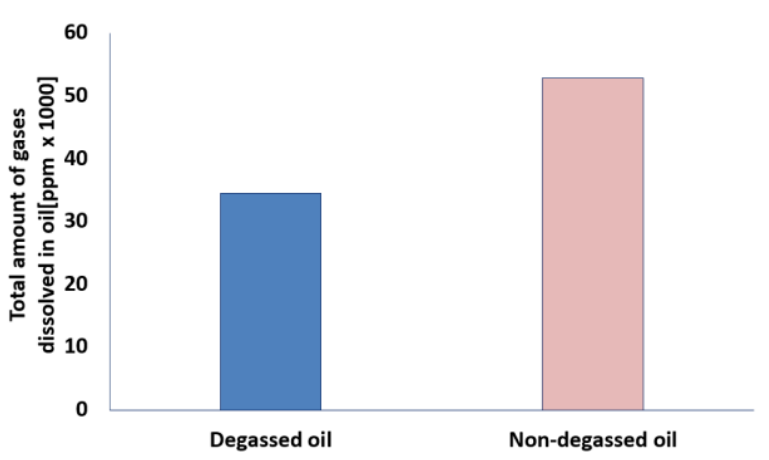

Fig. 1. Comparison of the total gas content in a degassed and non-degassed oil samples.

The gas chromatography results shown in Figure 1 confirm, that the prepared oil samples differ from each other in terms of the total dissolved gas content. Figure 2 presents the results of measurements of water content by the Karl Fischer titration method in the samples before the drying process and after drying by means of molecular sieves $3 \mathrm{~A}$ or $13 \mathrm{X}$.

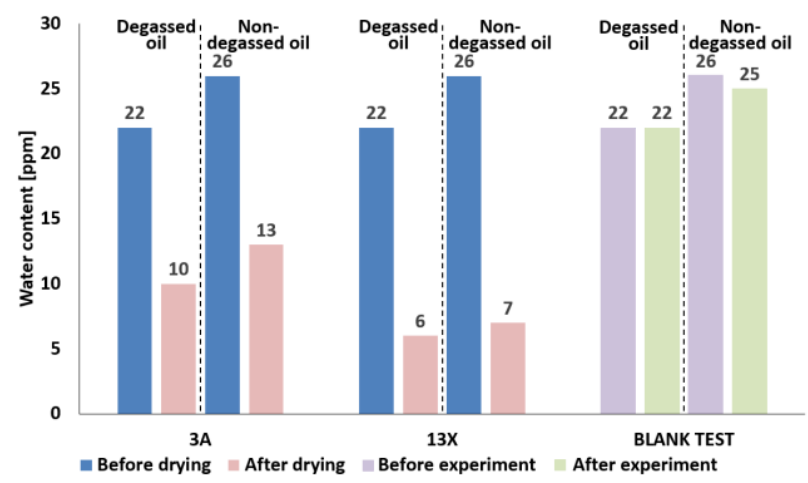

Fig. 2. The results of water content measurements.
Analyzing the results, it can be noticed that the water content in samples dried with molecular sieve $3 \mathrm{~A}$ decreased by approx. $55 \%$ in the case of degassed oil and about $50 \%$ in the case of non-degassed oil. In samples of oil dried with $13 \mathrm{X}$ molecular sieve, the water content decreased by approx. $72 \%$ for both, degassed oil and non-degassed oil. The water content in the one of the blank tests changed slightly. The water content in the blank test with non-degassed oil decreased by approx. $4 \%$.

Considering the above, it can be concluded that the effect of drying mineral oil by means of molecular sieves $3 \mathrm{~A}$ and $13 \mathrm{X}$, was similar for a given sieve type, regardless of whether the sample was degassed or not degassed. Small differences in the moisture of samples after drying result from the differences in the initial water content. The uncertainty of the coulometric water content measurement using the Karl Fischer titration method is about $1 \mathrm{ppm}$.

\section{Conclusions}

The tests have shown that in the analyzed range of gas content in mineral oil, they have no effect on the ability of $3 \mathrm{~A}$ and $13 \mathrm{X}$ molecular sieves for water sorption. This conclusion is very important due to the planned research consisting in the determination of water sorption isotherms of molecular sieves in transformer oil. Since the ability of molecular sieves for sorption of water in air is greater than their ability to sorption water in oil, the determination of water sorption isotherms in oil is necessary to estimate the effectiveness of drying the transformer insulation by means of molecular sieves. In the conducted research, the influence of atmospheric gasses was considered first of all. It is planned to conduct research, which will also allow to assess the impact of gasses used for transformer diagnostics (DGA method) on the ability of sieves for water sorption. The DGA method is a basic diagnostic tool for power transformers. Molecular sieves used for drying mineral oil should not adsorb diagnostic gasses, because it would make detection of defects arising during the operation of transformers difficult. The results of the tests described in this publication are the basis for further work.

\section{References}

1. M. Cybulski, P. Przybyłek, Przegląd Elektrotechniczny, R.94 N. 10, 37-40 (2018)

2. I. Fofana, V. Vasserberg, H. Borsi, E. Gockenbach, M. Farzaneh, IEEE Electrical Insulation Magazine, 20, 20-30 (2004)

3. Brochure, Cigre, 323 (2007)

4. IEC 60814 International Standard (1997) 